\title{
Factors influencing somatic embryogenesis, regeneration, and Agrobacterium-mediated transformation of cassava (Manihot esculenta Crantz) cultivar TME14
}

\author{
Evans N. Nyaboga, Joshua M. Njiru and Leena Tripathi * \\ Bioscience Center, International Institute of Tropical Agriculture, Nairobi, Kenya
}

\section{OPEN ACCESS}

Edited by:

Soren K. Rasmussen,

University of Copenhagen, Denmark

Reviewed by:

Ahmad Parveez Ghulam Kadir. Malaysian Palm Oil Board, Malaysia Makeshkumar Thangaraj, ICAR-Central Tuber Crops Research Institute, India

*Correspondence: Leena Tripathi, Bioscience Center, International Institute of Tropical Agriculture, P.O. Box 30709, Nairobi 00100, Kenya L.Tripathi@cgiar.org

Specialty section This article was submitted to

Plant Biotechnology,

a section of the journal Frontiers in Plant Science

Received: 27 February 2015 Accepted: 22 May 2015

Published: 10 June 2015

Citation:

Nyaboga EN, Njiru JM and Tripathi L (2015) Factors influencing somatic embryogenesis, regeneration, and

Agrobacterium-mediated transformation of cassava (Manihot esculenta Crantz) cultivar TME14.

Front. Plant Sci. 6:411.

doi: 10.3389/fpls.2015.00411
Routine production of large numbers of transgenic plants is required to fully exploit advances in cassava biotechnology and support development of improved germplasm for deployment to farmers. This article describes an improved, high-efficiency transformation protocol for recalcitrant cassava cultivar TME14 preferred in Africa. Factors that favor production of friable embryogenic calli (FEC) were found to be use of DKW medium, crushing of organized embryogenic structures (OES) through 1-2 mm sized metal wire mesh, washing of crushed OES tissues and short exposure of tyrosine to somatic embryos; and transformation efficiency was enhanced by use of low Agrobacterium density during co-cultivation, co-centrifugation of FEC with Agrobacterium, germination of paramomycin resistant somatic embryos on medium containing BAP with gradual increase in concentration and variations of the frequency of subculture of cotyledonary-stage embryos on shoot elongation medium. By applying the optimized parameters, FEC were produced for cassava cultivar TME14 and transformed using Agrobacterium strain LBA4404 harboring the binary vector pCAMBIA2301. About 70-80 independent transgenic lines per $\mathrm{ml}$ settled cell volume (SCV) of FEC were regenerated on selective medium. Histochemical GUS assays confirmed the expression of gusA gene in transformed calli, somatic embryos and transgenic plants. The presence and integration of the gusA gene were confirmed by PCR and Southern blot analysis, respectively. RT-PCR analysis of transgenic plants confirmed the expression of gusA gene. This protocol demonstrates significantly enhanced transformation efficiency over existing cassava transformation protocols and could become a powerful tool for functional genomics and transferring new traits into cassava.

Keywords: cassava, friable embryogenic calli, genetic transformation, co-centrifugation, transgenic plants

\section{Introduction}

Genetic transformation technology has become a high throughput platform for cultivar improvement in several crops as well as for studying gene function in plants. Despite cassava (Manihot esculenta Crantz) being an important staple food crop for millions of people throughout the tropics; research in the field of transgenic improvement and functional genomics in 
cassava is constrained by low efficiency and cultivar dependent transformation systems, and therefore an efficient transformation protocol, which does not necessitate further genotype specific standardization, is crucial for cassava genomics and improvement initiatives.

Currently, the use of friable embryogenic calli (FEC) has been considered the most preferred explants for Agrobacteriummediated transformation of cassava. Several protocols using FEC as target tissues and particle bombardment or Agrobacteriummediated transformation procedures have been reported (Taylor et al., 2012; Zainuddin et al., 2012; Nyaboga et al., 2013). However, establishing such embryogenic tissues is cultivar dependent and requires optimization of FEC production for each particular cultivar making it a prerequisite for agronomic improvement in that particular genetic background. Previous studies using the FEC-based cassava transformation method reported the introduction of important agronomic traits, such as reduced cyanogenesis, modified starch, and resistance to diseases (Liu et al., 2011; Vanderschuren et al., 2012). However, much progress has been made in the development of Agrobacteriummediated transformation protocols for the model cultivar 60444 (Bull et al., 2009; Taylor et al., 2012). Also the available genetic transformation systems have yielded only a few dozen or no transgenic lines for farmer-preferred cultivars since the available protocols are cultivar-dependent (Zainuddin et al., 2012). Hence, the development of efficient high-throughput genetic transformation capabilities for popular cassava cultivars is required.

"TME14" is a landrace commonly grown in West, Central, and East Africa and considered as one of the most preferred cultivars in Africa. It is ranked highest by farmers, being scored excellent for plant establishment, resistance to cassava mosaic disease (CMD), early maturation, high yield, mealiness, flavor, cooking qualities, and market value (NARO Report, 2005; Alicai et al., 2010). However, its production is severely affected by cassava brown streak disease (CBSD), cassava bacterial blight (CBB), and various insect pests such as whiteflies (Bemisia tabaci), mealybugs (Phenacoccus manihoti), and green mites (Mononychellus tanajoa Bondar) (Alicai et al., 2007; Ntawuruhunga and Legg, 2007; Herrera-Campo et al., 2011). Developing resistant varieties through genetic engineering potentially is the most costeffective and sustainable method of controlling diseases and pests. Such improvement initiatives demand a high-throughput cassava transformation system to produce more transgenic plants in shorter period. Agrobacterium-mediated transformation of TME14 has been reported, however, the efficiency was very low; only seven transgenic lines per 18 clumps of inoculated FEC were obtained (Zainuddin et al., 2012). Also this protocol was not able to be reproduced in our lab (Nyaboga et al., 2013). The low transformation efficiency for cultivar TME14, which account for more than $50 \%$ of the cultivated cassava, is unsatisfactory and much lower than that of model and some farmer-preferred cultivars (Bull et al., 2009; Taylor et al., 2012; Nyaboga et al., 2013). This suggests that standard cassava transformation protocol for generating a large number of transformants is limited to few cultivars, indicating that experimental parameters for cassava transformation have not been fully optimized for most of the farmer-preferred cultivars. As a contribution to this effort and cassava community, we set out to test combinations of parameters that have facilitated Agrobacterium-mediated transformation in other recalcitrant crops to improve the transformation efficiency of cassava cultivar TME14.

In the present study, we have developed an improved Agrobacterium-mediated transformation protocol for cassava cultivar TME14. In vitro culture conditions were optimized for efficient FEC induction from somatic embryos of cultivar TME14. We examined the effects of factors that favor somatic embryogenesis/production of FEC including use of DKW basal medium, wounding and washing of somatic embryos, and short exposure of tyrosine to somatic embryos. The critical point in developing an efficient transformation system is to optimize the right combination of several factors during transformation. We evaluated the effects of density of Agrobacterium suspension, Agrobacterium strains, and co-centrifugation of FEC and Agrobacterium cells, as these factors are known to improve transformation efficiency in other crops. To significantly improve the regeneration frequency of Agro-infected calli, we investigated the effect of stepwise increase in BAP concentration, explant size, addition of silver nitrate $\left(\mathrm{AgNO}_{3}\right)$, and frequency of subculturing of cotyledonary-stage embryos on shoot elongation medium. We then came up with a comprehensive protocol where all these modifications were combined to attain enhanced transformation and regeneration efficiency, thus overcoming the main hurdle in genetic manipulation of cassava. This protocol yields the highest number of transgenic lines reported to date for any cassava cultivar tested including cv. 60444, which is easy to transform. Therefore, it is appropriate for large scale production of transgenic plants needed for generation of T-DNA insertion as well as for gene targeting studies.

\section{Materials and Methods}

\section{Plant Material}

Plantlets of cassava landrace TME14 were obtained from in vitro germplasm collection of International Institute of Tropical Agriculture (IITA), Ibadan, Nigeria. The plantlets were maintained by regular sub-culturing at 4 weeks interval as in vitro plantlets on basic shoot culture medium (CBM, Supplementary Table 1 ) at $28^{\circ} \mathrm{C}$ under a $16 / 8 \mathrm{~h}$ photoperiod.

\section{Production of Somatic Embryos}

Somatic embryos (SE) were induced from axillary buds (AB) and immature leaf lobes (ILL) from 3 to 4 weeks old in vitro plantlets. Nodal explants ( $10 \mathrm{~mm}$ long) were cut and placed horizontally on petri dishes containing axillary bud enlargement medium (CAM, Supplementary Table 1) for 4 days at $28^{\circ} \mathrm{C}$ in the dark for production of axillary buds. The enlarged $A B$ from the nodal explants were removed with sterile syringe needles under a binocular microscope and transferred to callus induction medium (CIM, Supplementary Table 1) using either MS (Murashige and Skoog, 1962) or DKW (Driver and Kuniyuki, 1984) as the basal medium to evaluate the effect of different basal salt mixture media on production of somatic embryos. 
Similarly ILL (1-6 mm) were isolated and transferred to CIM using either MS or DKW as the basal medium. The plates with $\mathrm{AB}$ and ILL were incubated at $28^{\circ} \mathrm{C}$ in the dark for 2 and 4 weeks, respectively, to induce development of primary somatic embryos. The comparative potential of somatic embryogenesis was evaluated based on both the frequency of organized embryogenic structures (OES) production for each basal medium [Frequency of OES $=$ (total number of explants showing somatic embryogenesis/total explants cultured) $* 100$ ], and scoring of the amount of somatic embryos (SE) obtained per OES cluster on $0-5$ scale, where $0=$ no SE obtained, $1=$ very low SE, up to $10 \%$ of the OES cluster, $2=$ low SE, $11-25 \%$ of the OES, $3=$ medium SE, $26-50 \%$ of the OES, $4=$ high SE, $51-75 \%$ of the OES, and $5=$ very high SE with mostly structures embryogenic on entire OES cluster. The somatic embryos developed were subcultured onto fresh medium after removing non-embryogenic callus developing around the embryos with the help of sterile syringe needles. Four weeks old SE were used for the production of FEC.

\section{Production and Proliferation of Friable Embryogenic Calli (FEC)}

Production of FEC was performed according to the protocol described by Nyaboga et al. (2013) with several modifications. OES developed on CIM were collected onto a metallic wire mesh (pore size 1-2 $\mathrm{mm}$ ) and crushed with the help of spatula into small pieces by passing them though the mesh. Fine pieces of OES were transferred into a $50 \mathrm{ml}$ falcon tube and washed twice with double distilled sterile water followed by one wash with liquid Gresshoff and Doy (GD) medium (Gresshoff and Doy, 1974, Supplementary Table 1) containing $12 \mathrm{mg} / \mathrm{l}$ picloram and transferred to a $100 \mu \mathrm{m}$ nylon filter mesh and blotted on sterile paper towel. After removing the excess liquid, the filter was placed on GD media supplemented with $12 \mathrm{mg} / \mathrm{l}$ picloram and $12 \mathrm{mg} / \mathrm{l} \mathrm{L}$-tyrosine and incubated at $28^{\circ} \mathrm{C}$ in dark for 7 days. The crushed pieces of OES were transferred in clusters of 8-12 from the filter onto fresh GD medium supplemented with $12 \mathrm{mg} / \mathrm{l}$ picloram and incubated at $28^{\circ} \mathrm{C}$ in dark. FEC were subsequently grown at $28^{\circ} \mathrm{C}$ under $16 / 8 \mathrm{~h}$ photoperiod and sub-cultured onto fresh media every 3 weeks.

\section{Regeneration of FEC}

Assessment of the FEC regeneration potential was performed with 0.5 settled cell volume (SCV) of FEC tissues spread on nylon filter and cultured on embryo maturation and germination media (MSN; Supplementary Table 1 ) at $28^{\circ} \mathrm{C}$ under $16 / 8 \mathrm{~h}$ photoperiod and sub-cultured on fresh MSN media every 10 days. The cotyledonary-stage embryo were picked and transferred to cassava embryo maturation medium (CEM; Supplementary Table 1). After 10 days on CEM medium, the cotyledonary-stage embryos were transferred and placed on same medium after every 8-10 days. Germinating shoots were transferred to CBM for establishment of plantlets.

\section{Agrobacterium Strains, Plasmid Vector, and Preparation of Bacterial Cultures}

Agrobacterium tumefaciens strains EHA105 (Hood et al., 1993) and LBA4404 (Hoekema et al., 1983) harboring the
pCAMBIA2301 binary vector (CAMBIA, Canberra, Australia; http://www.cambia.org) was used for transformation. The T-DNA region of the plasmid pCAMBIA2301 contains the neomycin phosphotransferase gene (nptII) conferring kanamycin resistance to plant cells, and the reporter gene $\beta$-glucuronidase (gusA), in which the coding sequence is interrupted by an intron sequence (Supplementary Figure 1). Both $n p t \mathrm{II}$ and $g u s \mathrm{~A}$ genes are driven by the CaMV35S promoter. Agrobacterium cultures were prepared for transformation as described earlier (Nyaboga et al., 2013).

\section{Agrobacterium Inoculation and Co-Cultivation of FEC}

\section{Effect of Agrobacterium Density for Infectivity}

To investigate the effect of Agrobacterium density, the bacterial pellet was re-suspended in liquid GD medium supplemented with $200 \mu \mathrm{M}$ acetosyringone (Sigma Chemical Co.) adjusted to an $\mathrm{OD}_{600}$ of $0.1,0.25$, and 0.5 for transformation of FEC. Agrobacterium strain LBA4404 harboring pCAMBIA2301 was used for this treatment. Three months old FEC $(0.5 \mathrm{ml} \mathrm{SCV})$ were co-cultivated with $5 \mathrm{ml}$ culture of the Agrobacterium in sterile $50 \mathrm{ml}$ falcon tubes, mixed to disaggregate the callus tissues and incubated for $30 \mathrm{~min}$ with gentle shaking. After $30 \mathrm{~min}$ excess liquid was removed and Agro-inoculated FEC tissues were transferred onto a nylon filter mesh placed on sterilized paper towel for $5 \mathrm{~min}$ to remove excess bacteria. The filter having Agroinoculated FEC was then transferred onto co-cultivation medium (GD medium supplemented with $200 \mu \mathrm{M}$ acetosyringone) and incubated in the dark at $22^{\circ} \mathrm{C}$ for 3 days. After 3 days, transient gusA gene expression in Agro-infected FEC was compared based on blue stained spotted FEC.

\section{Comparison of Agrobacterium Strains for Infectivity}

Three months old FEC $(0.5 \mathrm{ml} \mathrm{SCV})$ were co-cultivated with two strains of A. tumefaciens, EHA105 and LBA4404 harboring pCAMBIA2301, to compare their infectivity. The ability of the strains to transfer T-DNA to the cassava FEC was compared through transient reporter gene expression.

\section{Effect of Co-Centrifugation of FEC and Agrobacterium Cells on Transformation Efficiency}

Effect of co-centrifugation of FEC and Agrobacterium cells on transformation efficiency was evaluated. An aliquot of $0.5 \mathrm{ml}$ SCV of FEC was suspended in GD medium containing $1.5 \mathrm{ml}$ of pre-induced Agrobacterium suspension. Two such treatment sets were made and labeled C (centrifuged) and NC (noncentrifuged). Each set of treatments had three replicates. The NC set of FEC were immersed in Agrobacterium cell suspension and incubated with gentle shaking at room temperature for $30 \mathrm{~min}$. The C set of FEC was co-centrifuged with Agrobacterium for $5 \mathrm{~min}$ at $1000 \mathrm{rpm}$ at room temperature and then incubated with gentle shaking at room temperature for $25 \mathrm{~min}$. After 3 days of co-cultivation, FEC were washed and transient gus A gene expression was recorded.

Following optimization, the best variable for each transformation parameters tested were combined and used for subsequent transformation experiments. 


\section{Selection and Regeneration of Transgenic Plants}

Following the co-cultivation step, Agro-infected FEC were washed three times with liquid GD medium containing $500 \mathrm{mg} / \mathrm{l}$ carbenicillin and transferred to nylon filter mesh, which was placed on GD media supplemented with $250 \mathrm{mg} / \mathrm{l}$ carbenicillin and incubated for 7 days at $28^{\circ} \mathrm{C} 16 / 8 \mathrm{~h}$ photoperiod. After 7 days of recovery phase, the nylon filter was transferred to fresh GD medium supplemented with $250 \mathrm{mg} / \mathrm{l}$ carbenicillin and $30 \mathrm{mg} / \mathrm{l}$ paramomycin and kept under $16 / 8 \mathrm{~h}$ photoperiod at $28^{\circ} \mathrm{C}$ for 7 days. This step was repeated twice with gradually increasing the paramomycin selection to 40 and $50 \mathrm{mg} / \mathrm{l}$. Following the FEC selection on GD media, the nylon filter with FEC was transferred to MSN medium supplemented with $250 \mathrm{mg} / \mathrm{l}$ carbenicillin and $50 \mathrm{mg} / \mathrm{l}$ paramomycin and kept under $16 / 8 \mathrm{~h}$ photoperiod at $28^{\circ} \mathrm{C}$ with fortnightly sub-culturing on fresh medium.

Various factors were evaluated in order to maximize the efficiency of regeneration of Agro-infected embryos:

\section{Effect of BAP Concentration on Regeneration of Agro-Infected Embryos}

Matured cotyledonary-stage embryos developing on selective MSN medium were transferred to shoot induction media (CEM) supplemented with $100 \mathrm{mg} / \mathrm{l}$ carbenicillin. The effect of gradually increasing concentration of BAP was evaluated on the shooting efficiency of cotyledonary-stage embryos. The cotyledons were placed on CEM medium with $0.1 \mathrm{mg} / \mathrm{l} \mathrm{BAP}$ for 10 days followed by transfer to CEM medium with $0.4 \mathrm{mg} / \mathrm{l} \mathrm{BAP}$ and compared with the treatment when embryos were cultured on either CEM with 0.1 or $0.4 \mathrm{mg} / \mathrm{l} \mathrm{BAP}$ only.

\section{Effect of Size of Explants}

The effect of size and section of the cotyledonary-stage embryos was also tested for the frequency of regeneration. Each cotyledonary-stage embryo was sliced either longitudinally or transversely and cultured on CEM media with stepwise increase of BAP concentration. The entire cotyledonary-stage embryo (without cutting) was also cultured on same medium for comparison.

\section{Effect of Silver Nitrate on Regeneration of Agro-Infected Embryos}

The role of silver nitrate $\left(\mathrm{AgNO}_{3}\right)$ on enhancement and shoot formation was investigated with cotyledonary-stage embryos obtained from MSN stage. The cotyledonary-stage embryos were cultured on CEM ( $0.1 \mathrm{mg} / \mathrm{l} \mathrm{BAP})$ medium supplemented with or without $\mathrm{AgNO}_{3}(4 \mathrm{mg} / \mathrm{l})$. After one cycle of 10 days in CEM (0.1 mg/l BAP), the embryos were transferred to CEM $(0.4 \mathrm{mg} / \mathrm{l}$ BAP) medium and further sub-culturing every 10 days onto fresh CEM (0.4 mg/l BAP) medium.

\section{Effect of Sub-Culturing Period on Regeneration of Agro-Infected Embryos}

The effect of increasing the subculture frequency of cotyledonary-stage embryos was also evaluated to determine its effect on germination efficiency of mature embryos. The cotyledonary-stage embryos were sub-cultured at a frequency of 8 and 14 days on CEM $(0.4 \mathrm{mg} / \mathrm{l} \mathrm{BAP})$ medium. A control experiment was used with no sub-culturing on CEM $(0.4 \mathrm{mg} / \mathrm{l}$ BAP) medium. The number of germinating embryos was recorded after 4 weeks of culture to calculate the regeneration frequency. Well-developed shoots $(3-5 \mathrm{~cm}$ long) from all the tested parameters were transferred to CBM for rooting and subsequent establishment of plantlets.

\section{GUS Histochemical Assay}

Histochemical assays for GUS activity were used to evaluate the effect of parameters influencing transformation efficiency. The GUS staining of callus and various explants (leaf, stem, and root) of putative transgenic plants was performed for transient and stable expression of gusA gene following the steps as earlier described (Nyaboga et al., 2013).

\section{PCR analysis}

Genomic DNA was extracted from young leaves of in vitro putative transgenic lines generated using DNAeasy plant mini kit (Qiagen, GmbH, Germany). The presence of gusA and nptII genes in the plant genome of the randomly selected putatively transgenic lines was confirmed by PCR analysis using gene-specific primers. The primer sequences for the gusA gene were: forward $5^{\prime}$-TTTAACTATGCCGGGATCCATCGC-3' and reverse $5^{\prime}$ CCAGTCGAGCATCTCTTCAGCGTA- $3^{\prime}$; and the $n p t$ II gene: forward 5'-GGGTGGAGAGGCTATTCGGCTATGA-3' $3^{\prime}$ and reverse $5^{\prime}$-ATTCGGCAAGCAGGCATCGC-3', corresponding to a 528 and 542 bp amplicon, respectively. Plasmid DNA of pCAMBIA2301 and non-transformed plant DNA were used as positive and negative controls, respectively. The reaction conditions for both primer pairs were $95^{\circ} \mathrm{C}$ for $5 \mathrm{~min}$; 35 cycles of $95^{\circ} \mathrm{C}$ for $30 \mathrm{~s}, 62^{\circ} \mathrm{C}$ for $40 \mathrm{~s}$, and $72^{\circ} \mathrm{C}$ for $50 \mathrm{~s}$; and a final 10 -min extension at $72^{\circ} \mathrm{C}$. PCR products were analyzed by gel electrophoresis on $1 \%(\mathrm{w} / \mathrm{v})$ agarose gels stained with GelRed ${ }^{\mathrm{TM}}$ (Biotium) and visualized under a UV transilluminator.

\section{Southern Blot Analysis}

Southern blot analysis was carried using the DIG DNA Labeling and Detection Kit (Roche Applied Sciences, Mannheim, Germany) according to the manufacturer's instructions. Genomic DNA was isolated from randomly selected PCRpositive in vitro grown plants using cetyltrimethylammonium bromide (CTAB) method (Soni and Murray, 1994). About $20 \mu \mathrm{g}$ of genomic DNA was digested overnight at $37^{\circ} \mathrm{C}$ with HindIII (New England Biolabs, USA) for which there is a single recognition site in the T-DNA of pCAMBIA2301, separated by electrophoresis on $0.8 \%(\mathrm{w} / \mathrm{v})$ agarose gel at $40 \mathrm{~V}$ for $6 \mathrm{~h}$, and transferred to Hybond-N+ nylon membrane (Roche) and fixed by cross-linking in a STRATA-LINK ${ }^{\mathrm{TM}}$ UV cross-linker. The blots were hybridized with digoxigenin (DIG)-labeled gusA-specific probe generated using a PCR DIG Probe Synthesis Kit (Roche Applied Sciences, Mannheim, Germany). Hybridization and detection were carried out using a DIG Luminescent Detection Kit for Nucleic Acids (Roche Applied Sciences, Mannheim, Germany), according to the manufacturer's instructions. 


\section{RNA Extraction and Reverse Transcriptase (RT)-PCR}

To examine transgenes expression, total RNA was isolated from $100 \mathrm{mg}$ young leaf tissue of nine randomly selected transgenic lines and non-transgenic control plant using the RNeasy plant mini kit and on-column DNase treatment according to the manufacturer's protocol (Qiagen, GmbH, Hilden, Germany). RNA quantity and purity were determined using a NanoDrop ND-2000 spectrophotometer (NanoDrop products, Wilmington, USA). Only RNA samples with $A_{260 / 280}$ ratios between 2.1 and 2.2 were further processed. RNA was checked with PCR for absence of genomic DNA. The first strand cDNA synthesis was performed using $2 \mu \mathrm{g}$ of total RNA and reverse transcriptase of the Maxima $\mathrm{H}$ Minus First Strand cDNA synthesis kit with oligo $(\mathrm{dT})_{18}$ primers (Thermo scientific, Waltham, MA) according to the manufacturer's instructions. RT-PCR was performed with $2 \mu \mathrm{l}$ of each cDNA synthesized using primers specific to the gusA gene (primer sequences as described above). Protein phosphatase 2A $(P P 2 A)$ amplification using genespecific primers: forward $5^{\prime}$-TGCAAGGCTCACACTTTCATC$3^{\prime}$ and reverse $5^{\prime}$-CTGAGCGTAAAGCAGGGAAG-3' was used as internal control to check the quality of synthesized cDNA. The amplified RT-PCR products were separated by gel electrophoresis on $1 \%(\mathrm{w} / \mathrm{v})$ agarose gels stained with GelRed ${ }^{\mathrm{TM}}$ (Biotium) and visualized under a UV transilluminator.

\section{Statistical Analysis}

All the experiments were conducted in triplicate. Each parameter for regeneration and transformation was tested in triplicates and repeated three times. The data were assessed by analysis of variance using GenStat. Data for the optimization experiments were analyzed using One-Way ANOVA and differences among treatment means were analyzed by Duncan's multiple-range test (DMRT) at a 95\% confidence level $(p<0.05)$.

\section{Results and Discussion}

Cassava remains popular staple food crop among resource poor farmers mostly due to its resilience and capacity to grow on marginal lands, and its flexible harvest period, which can be as long as 30 months after planting. It is, however, relatively low in nutrients and susceptible to several pests and diseases, including attacks from whitefly, mealybug, the widely-spread green mite, CBB, CMD, and CBSD, which significantly reduce cassava yields and pose a constraint to poor farmers with little or no response capacity (Herrera-Campo et al., 2011). The lack of resistance genes in the available germplasm, high heterozygosity, allopolyploidy, low fertility, and unsynchronized flowering make cassava improvement by conventional breeding a long and tedious process (Ceballos et al., 2004; Rudi et al., 2010). Therefore, cassava genetic engineering has emerged as a valuable alternative and complementary approach to improve cassava (Liu et al., 2011; Sayre et al., 2011). However, to be successful, these applications require efficient plant regeneration and transformation protocols for most agronomically important cassava cultivars. Development of such protocols particularly for farmer preferred cultivars required an in-depth study of factors affecting somatic embryogenesis, FEC production, Agrobacterium-mediated transformation and regeneration efficiency.

\section{Production of Somatic Embryos (SE) and Friable Embryogenic Calli (FEC)}

Efficient tissue culture systems are essential for the production of transgenic plants. With somatic embryogenesis forming the basis of all existing genetic transformation systems for this crop, research in our laboratory has focused on development of improved and highly efficient systems for the induction and manipulation of this process in a popular cassava cultivar TME14. OES and SE were obtained from both immature leaf lobe (ILL) and axillary bud (AB) explants cultured on either DKW or MS based medium supplemented with auxin picloram. The explant source (ILL or AB) as well as the basal media (DKW or MS) had significant $(p \leq 0.05)$ effects on the frequency of OES and efficiency of SE production (Figure 1). High frequencies of OES (90.19\% and $80.15 \%$ for $\mathrm{AB}$ and ILL, respectively) were formed when explants were cultured on DKW as compared to MS media (Figure 1). Also the frequencies of OES were high when $\mathrm{AB}$ was used as explants with both in DKW and MS based media compared with ILL (Figure 1). The formation of SE was observed after $12-16$ and 24-28 days using $A B$ and ILL explants, respectively. The highest scores (3.0-4.2) for SE production was obtained from $\mathrm{AB}$ on both media in comparison to ILL (1.7-2.3), demonstrating significantly higher efficiency of $\mathrm{SE}$ production from $\mathrm{AB}$ compared with ILL (Figure 1). The $\mathrm{AB}$ explants was used in further experiments as it had not only generated more primary SE, but also produced low quantities of non-embryogenic callus in comparison to ILL explants.

Use of DKW based media significantly increased the frequency of OES and SE production compared to MS medium from both $\mathrm{AB}$ and ILL (Figure 1). In all previous cassava transformation protocols reported, somatic embryos have been induced by culture of ILL or $\mathrm{AB}$ on $\mathrm{MS}$ based medium supplemented with auxin (Taylor et al., 2012; Vanderschuren et al., 2012; Zainuddin et al., 2012; Nyaboga et al., 2013). This study reports improved production of SE by using DKW basal media. Since, SE formation was found to be most efficient using $\mathrm{DKW}$ medium and $\mathrm{AB}$ as the explant in comparison to ILL, initiation of all the subsequent tissue culture for this investigation used DKW medium and AB explants.

Regular production of high quality FEC for use in Agrobacterium-mediated transformation experiments is essential for sustained production of transgenic plants. However, FEC induction strongly depends on the genotype (Liu et al., 2011). Several laboratories have made unremitting efforts by investigating various genotypes for FEC production, and success has been achieved in limited number of cultivars, such as TME1, TME7, TME14, T200, Serere, Ebwanatereka, TMS91/02327, Kibandameno, Rosinha, and Adira (Ibrahim et al., 2008; Zainuddin et al., 2012; Chetty et al., 2013; Nyaboga et al., 2013), although the efficiency of transformation is very low (only few dozen transgenic lines regenerated) and the protocol is not reproducible in different labs for example TME14 (Nyaboga et al., 2013). In all these previous studies FEC is induced from the 


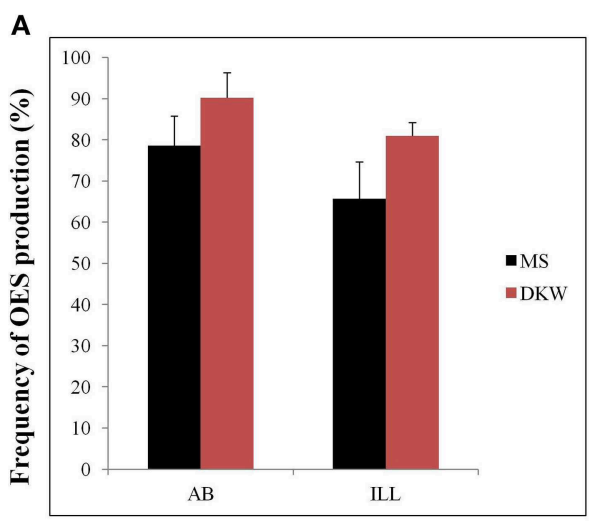

Explant type

FIGURE 1 | Organized embryogenic structures (OES) and primary somatic embryos (SE) produced by different types of explants (AB and ILL) on MS or DKW medium supplemented with $12 \mathrm{mg} / \mathrm{l}$ picloram. (A) Frequency of OES production from different type of explants cultured on MS or DKW basic medium. OES production frequencies were recorded by calculating the ratio of the total number of explants showing somatic

SE over three or more subculture cycles on GD supplemented with $12 \mathrm{mg} / \mathrm{l}$ picloram (Bull et al., 2009; Taylor et al., 2012; Zainuddin et al., 2012). In our previous study, transfer of somatic embryogenic structures of TME14 to GD medium following the previously reported protocols did not result in production of FEC (Nyaboga et al., 2013). FEC production was attempted in about 20 different induction experiments but none was successful. The consequence was that all attempts over a period of one and half years failed comprehensively to deliver any FEC tissues, despite daily and on-going experiments. The requisite for a reliable FEC production protocol for this cultivar generally evolved into an extensive re-evaluation of the procedure.

It has been reported previously that wounding of SE encourages FEC production (Taylor et al., 2012). In this study, rapid processing of the SE to produce FEC was improved by crushing the SE through 1-2 $\mathrm{mm}$ size metal wire mesh and washing with sterile water and GD media before culturing on GD medium containing $12 \mathrm{mg} / \mathrm{l}$ picloram and $12 \mathrm{mg} / \mathrm{l} \mathrm{L}$-tyrosine for 7 days and then transferring onto same media but without L-tyrosine for 3 weeks. Small groups of FEC became visible developing from the clusters of meshed SE within 3 weeks of culture on GD medium. This initial FEC was selectively removed from the non-embryogenic callus and used to establish the second cycle on GD containing $12 \mathrm{mg} / \mathrm{l}$ picloram and the process repeated 3 weeks later to generate a third cycle on the same medium, generating homogenous FEC suitable for transformation (Figure 2). These improvements resulted in a large amount of FEC production in three cycles of 21 days each on GD in comparison to six cycles for other farmerpreferred cultivars in previous reports (Nyaboga et al., 2013). However, crushed SE cultured on GD medium containing $12 \mathrm{mg} / \mathrm{l}$ picloram for 7 days (with or without tyrosine exposure) without washing turned brown and necrotic and did not result in

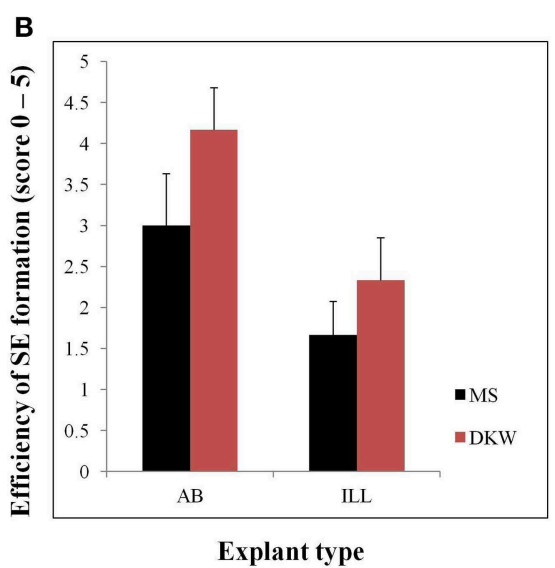

embryogenesis/total cultured explants ${ }^{*} 100$. (B) Efficiency of SE production from $A B$ and ILL explants. Scores are on a scale of 0-5 where 0, no SE obtained; 1 , very low SE, up to $10 \%$ of the OES cluster; 2, low SE, $11-25 \%$ of the OES; 3, medium SE, 26-50\% of the OES; 4, high SE, $51-75 \%$ of the OES; and 5, very high SE with mostly structures embryogenic on entire OES cluster.

FEC production after subsequent transfer to the same media for 3 weeks (Figure 2).

This protocol has been adopted in our lab for production of FEC of cultivar TME14 and even persons who had limited experience of tissue culture were able to generate FEC of moderate quality that could still be transformed and regenerated into plants. The factors that led to FEC production in TME14 compared to Nyaboga et al. (2013) includes the use of DKW medium, crushing of OES through 1-2 mm sized metal meshes, washing of the crushed OES structures and short exposure of tyrosine to somatic embryos.

\section{Effect of Cell Density of Agrobacterium Culture on Transformation Efficiency}

The ratio between Agrobacterium and host cell density is an important factor that influences T-DNA transfer frequency; low concentration of Agrobacterium may reduce the efficacy of TDNA transfer, while high concentration of bacteria may affect the viability of plant cells (Wang et al., 2009). The effect of $A$. tumefaciens concentration on transient expression of gusA gene in Agro-infected FEC tissues was determined using three different cell densities. The effect of bacterial densities on transformation was significantly $(p=0.05)$ different among $\mathrm{OD}_{600}$ of 0.1 and 0.25 , whereas it was not different for 0.25 and 0.5 (Table 1). Of the cell optical densities tested, the $\mathrm{OD}_{600}$ of 0.1 yielded the lowest frequency of GUS-positive calli $(25.59 \%)$ in comparison to the $\mathrm{OD}_{600}$ of $0.25(63.63 \%)$ and $0.5(66.31 \%)$ (Table 1$)$.

To determine the lowest but most effective Agrobacterium concentration suitable for regeneration of transgenic plants, we further investigated the effect of different Agrobacterium cell densities on the number of matured cotyledonary-stage embryos produced. Agrobacterium concentration of $\mathrm{OD}_{600}$ of 0.25 produced a significantly $(p=0.05)$ higher number 

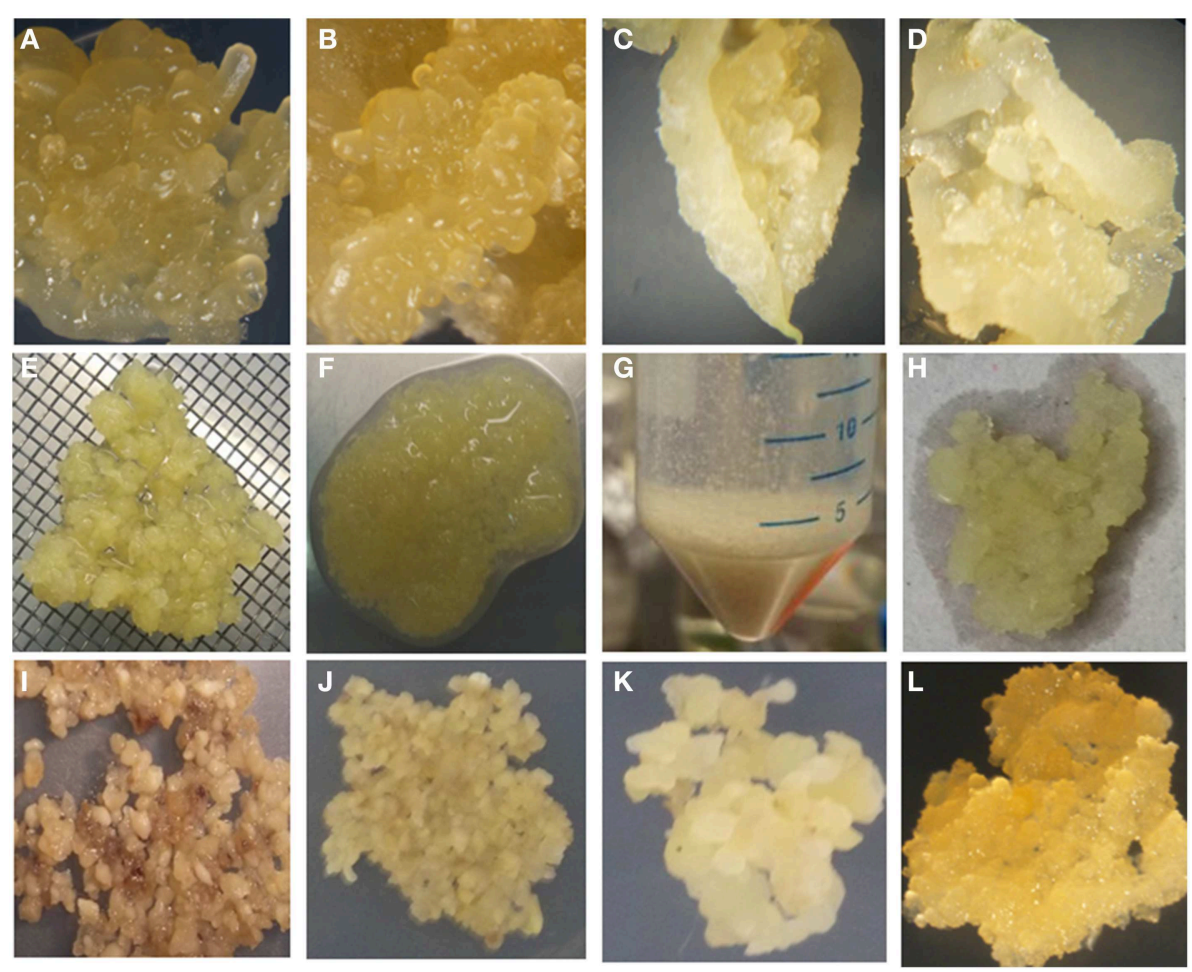

FIGURE 2 | Improved tissue culture steps for production of FEC of cultivar TME14. (A) Somatic embryos produced on MS medium using AB, (B) somatic embryos produced on DKW medium using AB, (C) somatic embryos produced on MS medium using ILL, (D) somatic embryos produced on DKW medium using ILL, (E) crushing of somatic embryos through 1-2 mm size metal wire meshes, (F) crushed somatic embryos tissues, (G) washing of crushed somatic embryos in falcon tubes,
(H) blotting of crushed somatic embryos after washing to remove liquid, (I) crushed somatic embryos tissues without washing and blotting spread evenly on GD medium supplemented with $12 \mathrm{mg} / \mathrm{l}$ tyrosine for 7 days, (J) crushed pieces of somatic embryos, washed, blotted and spread evenly on GD medium supplemented with $12 \mathrm{mg} / \mathrm{l}$ tyrosine for 7 days, (K) clusters of somatic embryos pieces on GD medium supplemented with $12 \mathrm{mg} / \mathrm{l}$ picloram, (L) proliferating FEC on GD medium.

TABLE 1 | Effect of Agrobacterium concentration, strains and co-centrifugation on transient GUS expression and number of cotyledonary stage embryos produced on selective medium.

\begin{tabular}{llrr}
\hline Factors & Treatments & $\begin{array}{c}\text { Frequency of transient } \\
\text { GUS expression (\%) }\end{array}$ & $\begin{array}{r}\text { Average no. of cotyledonary stage } \\
\text { embryos on selective medium }\end{array}$ \\
\hline Agrobacterium concentration & LBA4404 at $\mathrm{OD}_{600}$ of 0.1 & $25.59 \pm 4.17^{\mathrm{d}}$ & $59.67 \pm 4.16^{\mathrm{d}}$ \\
& $\mathrm{LBA4404}$ at $\mathrm{OD}_{600}$ of 0.25 & $63.63 \pm 4.73^{\mathrm{b}}$ & $131.33 \pm 8.02^{\mathrm{b}}$ \\
& $\mathrm{LBA4404}$ at $\mathrm{OD}_{600}$ of 0.5 & $66.31 \pm 2.50^{\mathrm{b}}$ & $71.33 \pm 9.29^{\mathrm{C}}$ \\
Agrobacterium strains & LBA4404 (OD 600 of 0.25$)$ & $65.38 \pm 4.12^{\mathrm{b}}$ & $137.45 \pm 7.32^{\mathrm{b}}$ \\
& EHA105 (OD 600 of 0.25$)$ & $64.29 \pm 5.33^{\mathrm{b}}$ & $133.22 \pm 11.21^{\mathrm{b}}$ \\
Co-centrifugation & Centrifugation (LBA4404, $\mathrm{OD}_{600}$ of 0.25$)$ & $91.22 \pm 4.48^{\mathrm{a}}$ & $153.67 \pm 8.62^{\mathrm{a}}$ \\
& No centrifugation (LBA4404, $\mathrm{OD}_{600}$ of 0.25$)$ & $62.28 \pm 3.96^{\mathrm{b}}$ & $130.33 \pm 11.02^{\mathrm{b}}$
\end{tabular}

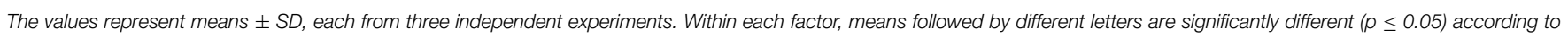
Duncan's multiple range test (DMRT).

of cotyledonary-stage embryos as compared with $\mathrm{OD}_{600}$ of 0.5 (Table 1). Based on gusA expression and production of cotyledonary-stage embryos, $\mathrm{OD}_{600}$ of 0.25 was selected for genetic transformation of cassava cultivar TME14. In cassava transformation, the effect of $A$. tumefaciens cell density $\left(\mathrm{OD}_{600}\right)$ on transient expression of gus A and transformation of cassava has not been reported in previous studies (Bull et al., 2009;
Taylor et al., 2012; Zainuddin et al., 2012; Nyaboga et al., 2013). In other plant species, the effect of Agrobacterium density on transformation efficiency is dependent on the species and/or cultivar (Dutt and Grosser, 2009). Therefore, the selection of optimum Agrobacterium cell density and suitable plant cultivar might be necessary to increase the transformation efficiency. The results of the present study showed that the optimal 
Agrobacterium concentration suitable for transformation of cassava cultivar TME14 is $\mathrm{OD}_{600}$ of 0.25 . These results are however contradictory to previous reports where an $\mathrm{OD}_{600}$ of 0.5 was recommended as an optimal Agrobacterium concentration for transformation of cassava (Bull et al., 2009; Taylor et al., 2012; Zainuddin et al., 2012; Nyaboga et al., 2013).

\section{Effect of Agrobacterium Tumefaciens Strains on Transformation Efficiency}

Agrobacterium strains play an important role in the transformation process, as they are responsible not only for infectivity but also for the efficiency of gene transfer (Bhatnagar and Khurana, 2003). The virulence of Agrobacterium strains varies widely among host plant species depending on the interaction between the Agrobacterium strain and host plant (Davis et al., 1991). So far Agrobacterium strain LBA4404 has been the only one used for cassava transformation (Bull et al., 2009; Taylor et al., 2012; Nyaboga et al., 2013) and the effect of Agrobacterium strains on cassava transformation has not been reported. In this study, we tested the efficiency of gene delivery using Agrobacterium strains, LBA4404 (Hoekema et al., 1983) and EHA105 (Hood et al., 1993). There was no significant difference between LBA4404 and EHA105 in both transient expression of gusA and number of antibiotic-resistant cotyledonary-stage embryos produced (Table 1). These results show that both Agrobacterium strains are suitable and efficient for transformation of cassava cultivar TME14. We used LBA4404 for transformation in the subsequent experiments.

\section{Effect of Co-Centrifugation of FEC and Agrobacterium Cells on Transformation Efficiency}

Co-centrifugation has been used to enhance Agrobacteriummediated transformation of banana embryogenic cell suspensions (Khanna et al., 2004; Tripathi et al., 2012). In the present investigation, a dramatic effect on the transformation efficiency of cassava FEC with Agrobacterium was observed following the use of centrifugal force for propelling the Agrobacterium cells into the cassava embryogenic calli. FEC co-centrifuged with Agrobacterium cells showed approximately 1.5-fold increase in transient expression of gus A gene as compared to the non-centrifuged treatment (Table 1). The observed increase in transient gene expression and stable transformation following co-centrifugation probably results from improved contact with host cells hence providing efficient delivery of T-DNA into cells as previously reported (Khanna et al., 2004). No previous study has been reported on the effect of co-centrifugation on the transformation efficiency in cassava.

\section{Optimization of Regeneration of Transgenic Plants}

The efficient germination of cotyledonary-stage embryos into plantlets is also an important step for whole plant regeneration and mass proliferation. The ability to regenerate complete plants from transformed cotyledonary-stage embryos is the main bottleneck of achieving high transformation efficiencies as observed in our previous study (Nyaboga et al., 2013). Low transformation efficiency in cassava due to poor germination of cotyledonary-stage embryos has also been reported in studies from other laboratories. Ihemere et al. (2006) reported development of only 26 transgenic plantlets from more than 872 paramomycin resistant cotyledonary-stage embryos from cassava genotype TMS71173. Similarly, Chetty et al. (2013) obtained only 33 transgenic lines from 514 hygromycin-resistant cotyledonary-stage embryos for cassava cultivar T200. In this study, preliminary experiments were performed to investigate the possibility of improving the germination efficiency of cultivar TME14 by evaluating the effect of gradual increasing concentrations of BAP, explant size, addition of silver nitrate $\left(\mathrm{AgNO}_{3}\right)$ and frequency of cotyledonary-stage embryos subculture to fresh media. The shoot formation was increased to $70.0 \%$ when cotyledonary-stage embryos were cultured on medium supplemented with $0.1 \mathrm{mg} / \mathrm{l}$ BAP for 2 weeks, followed by a transfer to the fresh medium supplemented with $0.4 \mathrm{mg} / \mathrm{l}$ BAP for 2-4 weeks, in comparison to when cotyledonary-stage embryos were cultured continuously on 0.1 or $0.4 \mathrm{mg} / \mathrm{l}$ BAP for 6 weeks for shoot induction and elongation step. These results indicate that low level of BAP $(0.1 \mathrm{mg} / \mathrm{l})$ was probably needed for the initiation of organ differentiation and thereafter a high concentration of BAP $(0.4 \mathrm{mg} / \mathrm{l})$ for shoot formation from cotyledons.

It has been reported from studies in different crops (such as sunflower, soybean, melon) that regeneration efficiency varies for the different sections of the cotyledonary region used (Leshem, 1989; Knittel et al., 1991; Baker et al., 1999; Vega et al., 2006). These studies found that when cotyledons were excised and divided perpendicularly to the long axis into proximal and distal sections, the proximal explants presented greater regeneration potential than distal ones. These differences in regeneration ability among regions from one cotyledon were attributed to the differential number of competent cells along the explants and/or the unequal distribution of endogenous growth regulators. In this study, the size and section of the cotyledonarystage embryos was tested to check if it had an effect on the frequency of regeneration. Each cotyledonary-stage embryo was sliced either longitudinally or transversely and cultured on CEM media with stepwise increase of BAP concentration. The frequency of regenerating cotyledonary-stage embryos and the number of shoots per cotyledon were affected by the size and section of cotyledonary-stage embryos used (Table 2). Longitudinal or transverse slicing of the cotyledon-stage embryos had negative effect on both the shooting efficiency and number of shoots regenerated per embryo (Table 2). The cotyledon-stage embryos devoid of lamina showed low regeneration frequency, as well as significant reduction in the number of shoots per cotyledon-stage embryo. These results showed that the cells capable of developing into shoots are located at the base of cotyledonary-stage embryo, but for expression of their full potential they require some unknown diffusible morphogenetic factor from lamina. This result could also be attributed to the fact that longitudinal/transverse slicing of cotyledonarystage embryos increased wound surface, which resulted in production of ethylene that negatively affected their regeneration ability (Kumar et al., 2009). Hence, whole cotyledonary-stage 


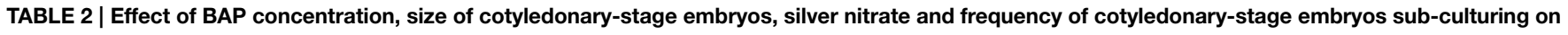
efficiency of in vitro germination and regeneration of plantlets of cassava cultivar TME14.

\begin{tabular}{|c|c|c|c|}
\hline Parameter tested & Treatment & $\begin{array}{c}\text { Germination } \\
\text { effeciency (\%) }\end{array}$ & $\begin{array}{l}\text { Mean no. of shoots } \\
\text { per cotyledonary stage embryos }\end{array}$ \\
\hline \multirow[t]{3}{*}{ BAP concentration } & BAP, $0.1 \mathrm{mg} / \mathrm{l}$ for 2 weeks followed by $0.4 \mathrm{mg} / \mathrm{l}$ for $2-4$ weeks & $70 \pm 6.67^{b}$ & $2 \pm 1.00^{b}$ \\
\hline & BAP, $0.4 \mathrm{mg} / \mathrm{l}$ for $2-6$ weeks & $40 \pm 3.33^{d}$ & $1.33 \pm 0.58^{C}$ \\
\hline & BAP, $0.1 \mathrm{mg} / \mathrm{l}$ for $2-6$ weeks & $41 \pm 4.27^{\mathrm{d}}$ & $1.03 \pm 0.35^{\mathrm{C}}$ \\
\hline \multirow[t]{3}{*}{ Size of cotyledonary staged embryos } & Entire cotyledonary staged embryos & $68.89 \pm 6.94^{b}$ & $2 \pm 1.00^{b}$ \\
\hline & Longitudinally sliced cotyledonary staged embryos & $36.67 \pm 6.67^{\mathrm{e}}$ & $1 \pm 0.00^{c}$ \\
\hline & Transverse proximal half of cotyledonary staged embryos & $46.67 \pm 3.33^{\mathrm{C}}$ & $1.33 \pm 0.57^{\mathrm{C}}$ \\
\hline \multirow[t]{2}{*}{ Silver nitrate } & $\mathrm{CEM}\left(\mathrm{No} \mathrm{AgNO}_{3}\right.$ added) & $71.11 \pm 6.94^{b}$ & $1.67 \pm 1.15^{\mathrm{b}}$ \\
\hline & CEM supplemented with $4 \mathrm{mg} / \mathrm{l} \mathrm{AgNO}_{3}$ & $67.78 \pm 8.39^{b}$ & $2.67 \pm 0.58^{a}$ \\
\hline \multirow[t]{3}{*}{ Sub-culturing frequency } & 8 days & $81.11 \pm 1.92^{\mathrm{a}}$ & $2 \pm 1.00^{b}$ \\
\hline & 14 days & $68.89 \pm 3.85^{b}$ & $1.67 \pm 0.57^{b}$ \\
\hline & No sub-culturing till shoot formation & $43.29 \pm 5.33^{d}$ & $1.13 \pm 0.33^{c}$ \\
\hline
\end{tabular}


indicate significant differences at $p \leq 0.05$ according to DMRT.

embryos were more efficient in germination and were used for regeneration of shoots in further experiments.

Silver nitrate has been shown to be effective in improving somatic embryogenesis and plant regeneration in a number of crop species including Brassica spp. (Eapen and George, 1997; Kuvshinov et al., 1999), maize (Carvalho et al., 1997), cowpea (Brar et al., 1999), peanut (Pestana et al., 1999), and barley (Castillo et al., 1998). As $\mathrm{Ag}^{+}$ions can prevent a wide variety of ethylene-induced plant responses, including growth inhibition and senescence, the effect is assumed to be mediated through the inhibition of the physiological action of ethylene (Beyer et al., 1984), a potential inhibitor of many plant regeneration systems (Kong and Yeung, 1994). In this study, we tested the effect of silver nitrate $\left(\mathrm{AgNO}_{3}\right)$ on regeneration of transformed embryos (Table 2). The supplementation of $\mathrm{AgNO}_{3}$ on regeneration media caused a significant increase in number of shoots per cotyledon but the germination efficiency of the cotyledons was not affected (Table 2) indicating that low regeneration efficiency of transformed embryos might not be due to ethylene production by cassava tissue in sealed tissue culture vessels.

Effect of sub-culture frequency on germination of cotyledonary-stage embryos was also investigated. It was found that frequent sub-culturing cotyledonary-stage embryos to fresh CEM media after every 8 days played a significant role in shooting of cotyledons (Table 2) when compared to sub-culturing every 14 days and no sub-culturing throughout the shooting period. The increase in frequency was beneficial to regeneration as there was an increase in the shoot development from cotyledonary-stage embryos. It is assumed that keeping cotyledonary-stage embryos on same medium for long leads to lose of germination potential.

\section{The Validation and Performance of the Optimized Transformation System}

Based on the above results, an optimized transformation system for cassava cultivar TME14 was developed (Figure 3) and further validated by large scale experiments. The system consisted of production of FEC for cultivar TME14, centrifugation, Agrobacterium strain LBA4404 with $\mathrm{OD}_{600}$ of 0.25 , a 3days co-cultivation period, selection on $50 \mathrm{mg} / \mathrm{l}$ paramomycin and regeneration on media with a stepwise increase of BAP concentration and sub-culture of cotyledonary-stage embryos after every 8 days. The protocol developed was reproducible as no significant $(p \leq 0.05)$ difference was observed in three different transformation experiments conducted and average of about 180-199 transgenic lines were generated from $2.5 \mathrm{ml} \mathrm{SCV}$ of Agro-infected FEC (Table 3).

Following co-inoculation with Agrobacterium, transformed FEC proliferated into small clusters of pale yellow colored resistant calli on paramomycin selection media (Figure 4A). Non-transformed calli stopped growing and turned whitish. Clusters of transformed FEC started developing into somatic embryos after transfer to MSN media (Figure 4B). After six cycles of 10 days each on MSN, FEC gave rise to a total of 713 putatively transformed cotyledonary-stage embryos from three independent experiments (Table 3). After two to three transfers to shoot induction and elongation media (CEM), cotyledonarystage embryos gave rise to shoots (Figure 4C-E). About 75$82 \%$ cotyledon-stage embryos formed shoots (Table 3 ). It is evident from this study that modification or optimization of the shoot stimulation protocol and more frequent transfers to CEM improved shooting efficiencies. No significant difference $(p \leq 0.05)$ in transformation efficiency was observed among the three experiments performed using different FEC lines. This contributes to the flexibility of the methodology, allowing induction and production of FEC lines to be initiated at different times.

Approximately 70-80 transgenic lines per $\mathrm{ml} \mathrm{SCV}$ (equivalent to 20 FEC clusters) were regenerated for cultivar TME14 in about 4-5 months from the time of Agrobacterium inoculation of FEC. This transformation frequency is significantly higher from previous reports. Bull et al. (2009) reported production 
Procedure

Grow in vitro TME14 plantlets, 3-4 weeks, $16 \mathrm{~h}$ light, $28^{\circ} \mathrm{C}$

Transfer stem-cuttings on CAM, 4 days, dark, $28^{\circ} \mathrm{C}$

Crushing of SE via a wire mesh and transfer to falcon tubes. Wash crushed

$\mathrm{SE}$, once with sterile $\mathrm{H}_{2} \mathrm{O}$ and twice with GD liquid

Place crushed tissues onto nylon filter, blot and transfer to

GD medium with $12 \mathrm{mg} / 1$ L-tyrosine, 7 days dark, $28^{\circ} \mathrm{C}$

Transfer SE pieces in clusters of $8-12$ on GD, 21 days, dark, $28^{\circ} \mathrm{C}$

Isolate $\mathrm{FEC}$ and culture on $\mathrm{GD}, 21$ days at $28^{\circ} \mathrm{C}$, repeat sub-culturing for up to

Transfer to nylon filter and culture on GD for co-cultivation carbenicillin $(500 \mathrm{mg} / \mathrm{l})$

Culture Agro-infected FEC on proliferation medium,

GD with carbenicillin $250 \mathrm{mg} / 1,4$ days, $16 \mathrm{~h}$ light, $28^{\circ} \mathrm{C}$

\section{$\checkmark$}

Transfer FEC to proliferation, selection medium, 1 week, $16 \mathrm{~h}$ light.

Repeat twice with increase in concentration of selection agent 7

Culture FEC on embryo emergence selection medium, MSN. Repeat for 8 weeks, $16 \mathrm{~h}$ light

1

Isolate developing cotyledonary-stage embryos on regeneration medium, CEM, 8-10 days, $16 \mathrm{~h}$ light, $28^{\circ} \mathrm{C}$. Repeat until shoots appear (2-4 weeks)

Transfer regenerated shoots to CBM medium, 3-4 weeks, $16 \mathrm{~h}$ light

$\downarrow$

Transfer to soil for hardening
Optimized treatment

Use of DKW for induction and multiplication of somatic embryos

Crushing of SE into small pieces, wash with sterile water followed by GD liquid prior to transfer to GD medium

Use of decreased concentration of L-tyrosine (12 mg/l) for 7 days on GD medium

Agrobacterium culture: $\mathrm{OD}_{600}$ of 0.25 ; Centrifugation for $5 \mathrm{~min}$ at 1000 rpm during infection

Use of stepwise increase in BAP concentrations; and increased frequency of subculture of cotyledonary-stage embryos on regeneration medium

FIGURE 3 | Schematic workflow of the protocol for production of FEC and Agrobacterium-mediated transformation of cassava cultivar TME14. The flow chart shows the essential steps optimized and followed in the protocol.

TABLE 3 | Generation of transgenic lines of cassava cultivar TME14 using Agrobacterium strain LBA4404 harboring pCAMBIA2301 following the optimized protocol.

\begin{tabular}{lccc}
\hline Experiment & $\begin{array}{c}\text { Total no. of } \\
\text { cotyledonary-stage } \\
\text { embryos produced on } \\
\text { selective medium }\end{array}$ & $\begin{array}{c}\text { Germination } \\
\text { efficiency } \\
(\mathbf{( \% )})^{\mathbf{b}}\end{array}$ & $\begin{array}{c}\text { Regenerated } \\
\text { transgenic } \\
\text { lines }^{\mathbf{c}}\end{array}$ \\
\hline A & 240 & 75.78 & 180 \\
B & 244 & 82.93 & 199 \\
C & 229 & 79.73 & 181 \\
\hline
\end{tabular}

Approximately $2.5 \mathrm{ml}$ SCV of different FEC lines was used in each experiment.

a Total number of putatively transformed cotyledonary-stage embryos emerging from $2.5 \mathrm{~m} / \mathrm{SCV}$ of FEC on selective medium supplemented with $50 \mathrm{mg} / \mathrm{l}$ paramomycin.

${ }^{b}$ Calculated as the number of shoots obtained on CEM divided by the total number of transformed cotyledonary-stage embryos cultured.

${ }^{c}$ Total number of transgenic lines generated from $2.5 \mathrm{~m} / \mathrm{SCV}$ of FEC.

of up to 50 transgenic plants after Agrobacterium-mediated transformation of 100 clusters of FEC of model cultivar 60444. Zainuddin et al. (2012) reported 7-17 transgenic lines per
18 clusters of FEC of TME cassava landraces. Chetty et al. (2013) reported 23 transgenic lines per 100 clusters of FEC of cassava cultivar T200. Taylor et al. (2012) obtained 14.3-28.6 transgenic plants per $\mathrm{cm}^{3}$ of SCV of FEC of model cultivar 60444 . Comparison of transformation frequency obtained for the model cultivar 60444, TME landraces and farmer-preferred cultivars in previous reports demonstrated that transformation efficiency reported here is significantly $(p \leq 0.05)$ higher suggesting that the optimized transformation protocol is robust and highthroughput. The lack of significant variation in transformation efficiency between independent experiments and the lack of failed experiments also adds to the utility of the method as reliable research tool.

This optimized protocol opens the doors to the introduction of desirable traits like virus resistance into TME14. To test the adaptability of this protocol, transformation and regeneration capabilities in further cassava transformation experiments were performed for virus resistance (data not shown). About 1100 transgenic lines were regenerated from a total of $10 \mathrm{ml}$ of SCV of FEC in four independent transformation experiments. 

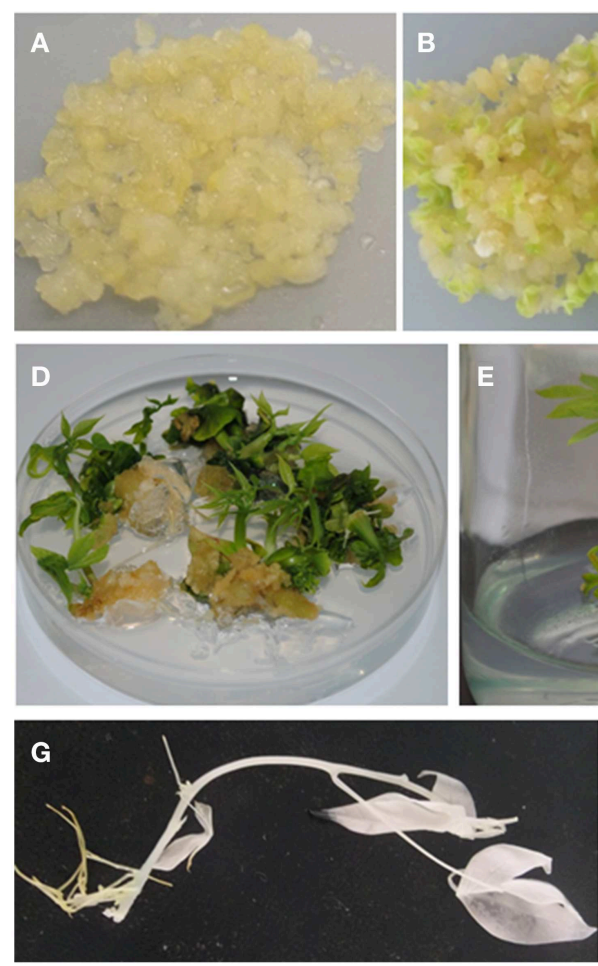

FIGURE 4 | Agrobacterium-mediated genetic transformation of FEC of cassava cultivar TME14 and histochemical GUS assays of transformed and non-transformed tissues. (A) Agrobacterium-infected FEC proliferating on selective medium, (B) developing embryos on embryo induction medium, (C) maturing cotyledonary-stage embryos on shoot induction medium,
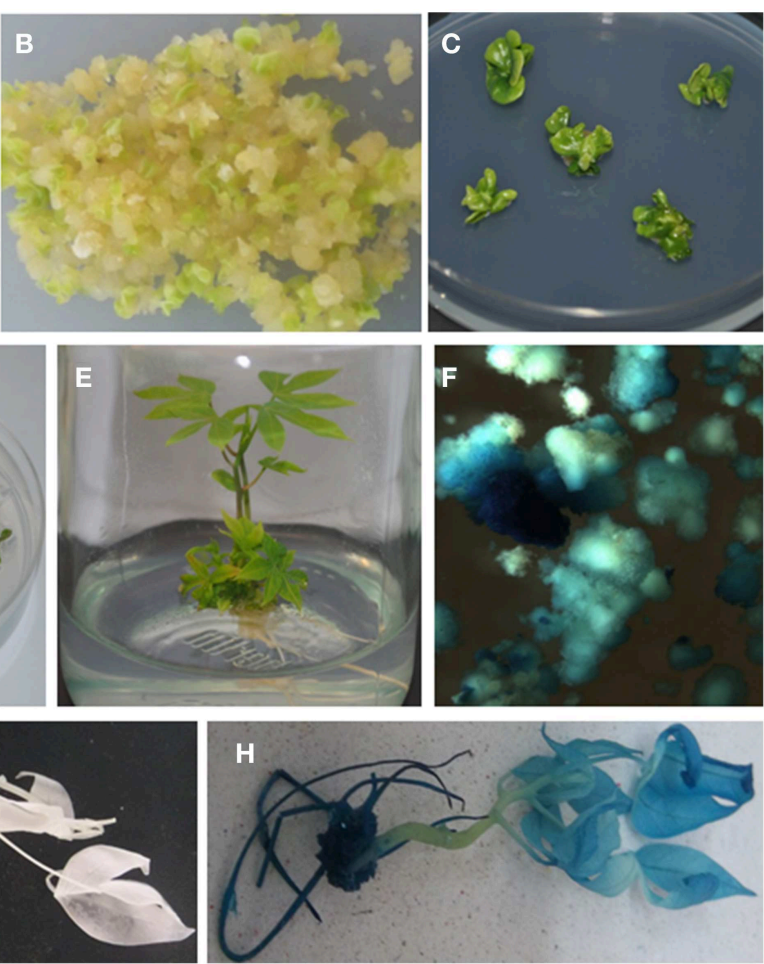

This suggests that the optimized and validated transformation procedure is reproducible and highly efficient in comparison to previous protocols reported (Bull et al., 2009; Taylor et al., 2012; Zainuddin et al., 2012). Our results suggest that the protocol presented here is useful for introducing functional genes into cassava cultivar TME14.

\section{Histochemical GUS Analysis of Transgenic Lines}

Expression of the gusA-intron gene is a reliable indicator of plant transformation, since the gene only can express efficiently in plant cells but not in Agrobacterium (Vancanneyt et al., 1990). Transient GUS expression assay 3 days after co-cultivation of FEC tissues showed blue coloration confirming transient expression of the reporter gene in friable embryogenic cells (Figure 4F). A uniform blue coloration was observed in all plants tested from randomly selected transgenic lines, confirming stable expression of gusA gene throughout the plant indicating uniform transformation had occurred (Figure 4H). No blue coloration was observed in non-transformed regenerated plants (Figure 4G).

\section{Molecular Analysis of Transgenic Lines}

The presence of transgene in paramomycin resistant regenerated putative transgenic plants was confirmed by PCR analysis. The
(D) germination of cotyledonary-stage embryos on shoot induction and elongation medium, (E) transgenic plantlets regenerated on selective medium, (F) transient expression of gusA gene in FEC tissues 3 days after co-cultivation with Agrobacterium, (G) no expression of gusA gene in non-transgenic plant, $\mathbf{( H )}$ stable expression of gusA gene in transgenic plant.
$528 \mathrm{bp}$ of gusA and $542 \mathrm{bp}$ of $n p t \mathrm{II}$ genes were successfully amplified from all the transgenic lines confirming presence of the gene in plant's genome (Figure 5A). No amplification product was detected in non-transgenic control plants.

To determine stable integration of transgene into the plant's genome, Southern blot analysis was performed on randomly selected PCR-positive transgenic lines and a non-transgenic control using a DIG-labeled DNA probe corresponding to the gus A gene. All selected plants showed hybridization signals confirming the genomic integration of the transgene (Supplementary Figure 2). Different sizes of bands from the Southern blot experiment represented that the insertion of T-DNA was on different location of the genome. No hybridization was observed in the non-transgenic control plant.

The expression of gusA gene was confirmed by RT-PCR analysis. An expected 528 bp fragment was amplified from the cDNA products of transgenic lines, but was absent in non-transgenic plants (Figure 5B). Specific PP2A transcript amplification was detected from all plants as an internal control for cDNA synthesis. These results demonstrated that gusA transgene was successfully incorporated into the genome of regenerated plants and functionally expressed transgenic cells. 


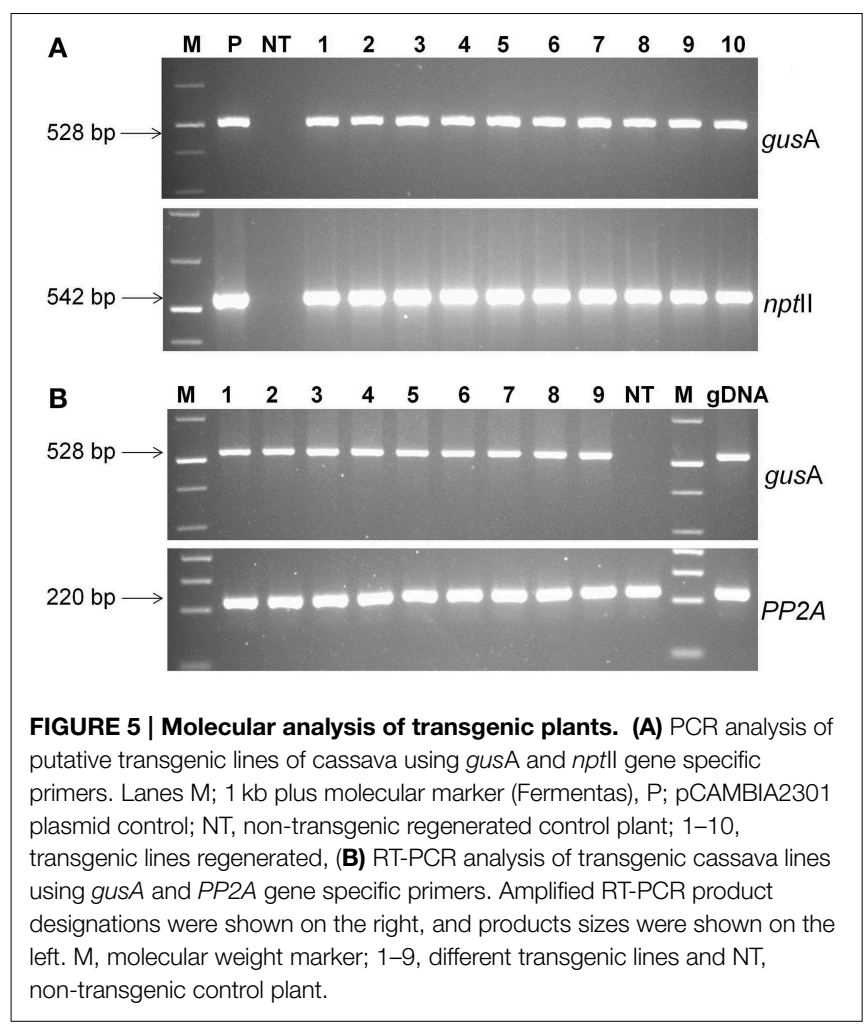

\section{Conclusions}

We report here the development of a high-throughput system for Agrobacterium-mediated transformation and regeneration of an important farmer preferred cassava cultivar "TME14" using FEC. We have made improvements in tissue culture and regeneration protocols that will make the production of transgenic cassava plants more efficient than the protocols described in earlier reports. Transformed FEC generated plants with high efficiency, at 70-80 transgenic lines per $\mathrm{ml}$ of SCV. This high-throughput method could be used for studying gene manipulation and transferring new traits into farmer preferred cassava cultivar

\section{References}

Alicai, T., Omongo, C. A., Kawuki, R., Pariyo, A., Baguma, Y., and Bua, A. (2010). National Cassava Programme-Uganda, 2009 National Survey.

Alicai, T., Omongo, C. A., Maruthi, M. N., Hillocks, R. J., Baguma, Y., Kawuki, R., et al. (2007). Re-emergence of cassava brown streak disease in Uganda. Plant Dis. 91, 24-29. doi: 10.1094/PD-91-0024

Baker, C. M., Muñoz-Fernandez, N., and Carter, C. D. (1999). Improved shoot development and rooting from mature cotyledons of sunflower. Plant Cell Tissue Organ Cult. 58, 39-49.

Beyer, E. M., Morgan, J. P. W., and Yang, S. F. (1984). “Ethylene," in Advanced Plant Physiology, ed M. B. Wilkins (Bath: Pitman Press), 111-126.

Bhatnagar, S., and Khurana, P. (2003). Agrobacterium tumefaciens-mediated transformation of Indian mulberry, Morus indica cv. K2: a time-phased screening strategy. Plant Cell Rep. 21, 669-675. doi: 10.1007/s00299-003-0572-2

Brar, M. S., Moore, M. J., Al Khayri, J. M., Morelock, T. E., and Anderson, E. J. (1999). Ethylene inhibitors promote in vitro regeneration of cowpea (Vigna
TME14. We have already generated over a thousand transgenic TME14 lines using this protocol as a step toward developing CBSD resistance. This protocol can be applied to other farmer preferred cultivars of cassava. We have tested the adaptability of this protocol in another farmer preferred cultivars like "Albert" and "Mkombozi," which were found to be difficult to transform in our previous study (Nyaboga et al., 2013). The factors which favored somatic embryogenesis in TME14, also able to produce FEC in "Albert" and "Mkombozi." By applying improved transformation protocol for TME14, the FEC of these two cultivars were transformed using gus A reporter gene and transgenic lines were generated with transformation efficiencies similar to TME14, suggesting that the Agrobacterium-mediated transformation protocol developed for TME14 can be adapted to other important cultivars for crop improvement.

\section{Acknowledgments}

The authors would like to thank United States Agency for International Development (USAID) for financial support of this work. We wish to express our appreciation to the Biosciences eastern and central Africa (BecA) based at International Livestock Research Institute in Nairobi, Kenya for providing the laboratory facilities. We acknowledge Anne Wanjohi for technical assistance.

\section{Supplementary Material}

The Supplementary Material for this article can be found online at: http://journal.frontiersin.org/article/10.3389/fpls.2015. 00411/abstract

Supplementary Figure 1 | Schematic representation of gene construct used for genetic transformation of cassava. The T-DNA region of construct pCAMBIA2301 with gusA and nptll genes. nptll, coding region of the neomycin phosphotransferase gene; NOS, nopaline synthase terminator; intron-gusA, $\beta$-glucuronidase containing intron; MCS, multiple cloning site; 35SP, CAMV35S promoter.

Supplementary Figure 2 | Southern analysis of genomic DNA of transgenic lines and non-transgenic control plant (NT) using HindllI restriction enzyme.

unguiculata L.). In Vitro Cell. Dev. Biol. 35, 222-225. doi: 10.1007/s11627-9990082-1

Bull, S. E., Owiti, J. A., Niklaus, M., Beeching, J. R., Gruissem, W., and Vanderschuren, H. (2009). Agrobacterium-mediated transformation of friable embryogenic calli and regeneration of transgenic cassava. Nat. Protoc. 4, 1845-1854. doi: 10.1038/nprot.2009.208

Carvalho, C. H. S., Bohorova, N., Bordallo, P. N., Abreu, L. L., Valicente, F. H., Bressan, W., et al. (1997). Type II callus production and plant regeneration in tropical maize genotypes. Plant Cell Rep. 17, 73-76. doi: 10.1007/s002990050355

Castillo, A. M., Egana, B., Sanz, J. M., and Cistue, L. (1998). Somatic embryogenesis and plant regeneration from barley cultivars grown in Spain. Plant Cell Rep. 17, 902-906. doi: 10.1007/s002990050506

Ceballos, H., Iglesias, C. A., Perez, J. C., and Dixon, A. G. O. (2004). Cassava breeding: opportunities and challenges. Plant Mol. Biol. 56, 503-516. doi: 10.1007/s11103-004-5010-5

Chetty, C. C., Rossin, C. B., Gruissem, W., Vanderschuren, H., and Rey, M. E. C. (2013). Empowering biotechnology in southern Africa: establishment of 
a robust transformation platform for the production of transgenic industrypreferred cassava. N. Biotechnol. 30, 136-143. doi: 10.1016/j.nbt.2012.04.006

Davis, M., Lineberger, D., and Miller, R. A. (1991). Effects of tomato cultivar, leaf age, and bacterial strain on transformation by Agrobacterium tumefaciens. Plant Cell Tissue Organ Cult. 24, 115-121. doi: 10.1007/BF00039739

Driver, J. A., and Kuniyuki, A. N. (1984). In vitro propagation of Paradox walnut rootstock. Hortic. Sci. 19, 507-509.

Dutt, M., and Grosser, J. W. (2009). Evaluation of parameters affecting Agrobacterium-mediated transformation of citrus. Plant Cell Tissue Organ Cult. 98, 331-340. doi: 10.1007/s11240-009-9567-1

Eapen, S., and George, L. (1997). Plant regeneration from peduncle segments of oil seed Brassica species: influence of silver nitrate and silver thiosulfate. Plant Cell Tissue Organ Cult. 51, 229-232. doi: 10.1023/A:1005926108586

Gresshoff, P., and Doy, C. (1974). Derivation of a haploid cell line from Vitis vinifera and the importance of the stage of meiotic development of anthers for haploid culture of this and other genera. Z. Pflanzenphysiol. 73, 132-141. doi: 10.1016/S0044-328X(74)80084-X

Herrera-Campo, V., Hyman, G., and Bellotti, A. (2011). Threats to cassava production known and potential geographic distribution of four key biotic constraints. Food Sec. 3, 329-345. doi: 10.1007/s12571-011-0141-4

Hoekema, A., Hirsch, P. R., Hooykaas, P. J. J., and Schilperoort, R. A. (1983). A binary vector strategy based on separation of vir and T-region of the Agrobacterium tumefaciens Ti plasmid. Nature 303, 179-180. doi: $10.1038 / 303179 \mathrm{a} 0$

Hood, E. E., Gelvin, S. B., Melchers, L. S., and Hoekema, A. (1993). New Agrobacterium vectors for plant transformation. Transgenic Res. 2, 208-218. doi: 10.1007/BF01977351

Ibrahim, A. B., Heredia, F. F., Pinheiro, C. B., Aragao, F. J. L., and Campos, F. A. P. (2008). Optimization of somatic embryogenesis and selection regimes for particle bombardment of friable embryogenic callus and somatic cotyledons of cassava (Manihot esculenta Crantz). Afr. J. Biotechnol. 7, 2790-2797. doi: 10.5897/AJB08.249

Ihemere, U., Arias-Garzon, D., Lawrence, S., and Sayre, R. (2006). Genetic modification of cassava for enhanced starch production. Plant Biotechnol. J. 4, 453-465. doi: 10.1111/j.1467-7652.2006.00195.x

Khanna, H., Becker, D., Kleidon, J., and Dale, J. (2004). Centrifugation Assisted Agrobacterium tumefaciens-mediated Transformation (CAAT) of embryogenic cell suspensions of banana (Musa spp. Cavendish AAA and Lady Finger AAB). Mol. Breed. 14, 239-252. doi: 10.1023/B:MOLB.0000047771.34186.e8

Knittel, N., Escandón, A. S., and Hahne, G. (1991). Plant regeneration at high frequency from mature sunflower cotyledons. Plant Sci. 73, 219-226. doi: 10.1016/0168-9452(91)90031-3

Kong, L., and Yeung, E. C. (1994). Effects of ethylene and ethylene inhibitors on white spruce somatic embryo maturation. Plant Sci. 104, 71-80. doi: 10.1016/0168-9452(94)90192-9

Kumar, V., Parvatam, G., and Ravishankar, G. A. (2009). $\mathrm{AgNO}_{3}-$ a potential regulator of ethylene activity and plant growth modulator. Electron. J. Biotechnol. 12, 1-15. doi: 10.2225/vol12-issue2-fulltext-1

Kuvshinov, V., Koivu, K., Kanerva, A., and Pehu, E. (1999). Agrobacterium tumefaciens-mediated transformation of greenhouse grown Brassica rapa ssp. oleifera. Plant Cell Rep. 18, 773-777. doi: 10.1007/s002990050659

Leshem, B. (1989). Polarity and responsive regions for regeneration in the cultured melon cotyledon. J. Plant Physiol. 135, 237-239. doi: 10.1016/S01761617(89)80184-1

Liu, J., Zheng, Q., Ma, Q., Gadidasu, K. K., and Zhang, P. (2011). Cassava genetic transformation and its application in breeding. J. Integr. Plant Biol. 53, 552-569. doi: 10.1111/j.1744-7909.2011.01048.x

Murashige, T., and Skoog, F. (1962). A revised medium for rapid growth and bioassays with tobacco tissue cultures. Physiol. Plant 15, 473-497. doi: 10.1111/j.1399-3054.1962.tb08052.x

Ntawuruhunga, P., and Legg, J. P. (2007). New Spread of Cassava Brown Streak Virus Disease and Its Implications for the Movement of Cassava Germplasm in the East and Central African Region, 2007. Ibadan: Crop Crisis Control Project report, International Institute of Tropical Agriculture, 1-6.

Nyaboga, E., Njiru, J., Nguu, E., Gruissem, W., Vanderschuren, H., and Tripathi, L. (2013). Unlocking the potential of tropical root crop biotechnology in east Africa by establishing a genetic transformation platform for local farmerpreferred cassava cultivars. Front. Plant Sci. 4:526. doi: 10.3389/fpls.2013. 00526

Pestana, M. C., Lacorte, C., de Freitas, V. G., de Oliveira, D. E., and Mansur, E. (1999). In vitro regeneration of peanut (Arachis hypogaea L.) through organogenesis: effect of culture temperature and silver nitrate. In Vitro Cell. Dev. Biol. 35, 214-216. doi: 10.1007/s11627-999-0080-3

Rudi, N., Norton, G. W., Alwang, J., and Asumugha, G. (2010). Economic impact analysis of marker-assisted breeding for resistance to pests and postharvest deterioration in cassava. Afr. J. Agric. Res. Econ. 4, 110-122.

Sayre, R., Beeching, J., Cahoon, E., Egesi, C., Fauquet, C., Fellman, J., et al. (2011). The BioCassava Plus Program: biofortification of cassava for subSaharan Africa. Annu. Rev. Plant Biol. 62, 251-272. doi: 10.1146/annurevarplant-042110-103751

Soni, R., and Murray, J. A. (1994). Isolation of intact DNA and RNA from plant tissues. Anal. Biochem. 218, 474-476. doi: 10.1006/abio.1994.1214

Taylor, T., Gaitán-Solís, E., Moll, T., Trauterman, B., Jones, T., Pranjal, A., et al. (2012). A high-throughput platform for the production and analysis of transgenic cassava (Manihot esculenta) plants. Trop. Plant Biol. 5, 127-139. doi: 10.1007/s12042-012-9099-4

Tripathi, J. N., Muwonge, A., and Tripathi, L. (2012). Efficient regeneration and transformation protocol for plantain cultivar 'Gonja Manjaya' (Musa spp. AAB) using embryogenic cell suspension. In Vitro Cell Dev. Biol. 48, 216-224. doi: 10.1007/s11627-011-9422-z

National Cassava Programme-Uganda Report. (2005). Integration of Gender, SocioEconomic and Market Factors for Expanded Cassava Production in the Teso and Lango Farming Systems. NARO/DFID CORF3029 Project Terminal Report.

Vancanneyt, G., Schmidt, R., O'Connor-Sanchez, A., Willmitzer, L., and RochaSosa, M. (1990). Construction of an intron-containing marker gene: splicing of the intron in transgenic plants and its use in monitoring early events in Agrobacterium-mediated plant transformation. Mol. Gen. Genet. 220, 245-250.

Vanderschuren, H., Moreno, I., Anjanappa, R. B., Zainuddin, I. M., and Gruissem, W. (2012). Exploiting the combination of natural and genetically engineered resistance to cassava mosaic and cassava brown streak viruses impacting cassava production in Africa. PLoS ONE 7:e45277. doi: 10.1371/journal.pone. 0045277

Vega, T. A., Nestares, G. M., Zorzoli, R., and Picardi, L. (2006). Responsive regions for direct organogenesis in sunflower cotyledons. Acta Physiol. Plant 28, 427-431. doi: 10.1007/BF02706625

Wang, B., Liu, L., Wang, X., Yang, J., Sun, Z., Zhang, N., et al. (2009). Transgenic ramie [Boehmeria nivea (L.) Gaud.]: factors affecting the efficiency of Agrobacterium tumefaciens-mediated transformation and regeneration. Plant Cell Rep. 28, 1319-1327. doi: 10.1007/s00299-009-0732-0

Zainuddin, I., Schlegel, K., Gruissem, W., and Vanderschuren, H. (2012). Robust transformation procedure for the production of transgenic farmer-preferred cassava cultivars. Plant Methods 8:24. doi: 10.1186/1746-4811-8-24

Conflict of Interest Statement: The authors declare that the research was conducted in the absence of any commercial or financial relationships that could be construed as a potential conflict of interest.

Copyright (C) 2015 Nyaboga, Njiru and Tripathi. This is an open-access article distributed under the terms of the Creative Commons Attribution License (CC BY). The use, distribution or reproduction in other forums is permitted, provided the original author(s) or licensor are credited and that the original publication in this journal is cited, in accordance with accepted academic practice. No use, distribution or reproduction is permitted which does not comply with these terms. 